\title{
Swine infection by Streptococcus suis: a retrospective study
}

\author{
[Infecção em suínos por Streptococcus suis: estudo retrospectivo] \\ A.E. Del'Arco ${ }^{1}$, J.L. Santos $^{2}$, P.D. Bevilacqua ${ }^{3}$, J.E. Faria ${ }^{3}$, W.V. Guimarães ${ }^{2}$ \\ ${ }^{1}$ Departamento de Ciências Agrárias e Ambientais - UESC \\ Rodovia Ilhéus - Itabuna, km 16 \\ 45650-000 - Ilhéus, BA \\ ${ }^{2}$ Microvet - Microbiologia Veterinária Especial Ltda. - Viçosa, MG \\ ${ }^{3}$ Departamento de Veterinária - UFV - Viçosa, MG
}

\begin{abstract}
The epidemic aspects of swine infections caused by Streptococcus suis were studied, focusing mainly on the occurrence of several serotypes. A total of 323 samples of $S$. suis were isolated from clinically ill animals, serotyped according to the co-agglutination procedure, and analyzed. The serotyping revealed that $S$. suis was present in several Brazilian states. The largest number was isolated from the states of Minas Gerais (62.5\%), São Paulo (10.8\%), and Paraná (9.3\%). Serotype 2 was the most frequent (61.0\%), followed by the serotypes $1,3,4,7$, and 8 . The largest number of isolations was obtained from the brain (60.1\%), followed by the lungs $(10.4 \%)$. About $9.4 \%$ of the cases were due to septicemia.
\end{abstract}

Keywords: pig, Streptococcus suis, serotypes

\section{RESUMO}

Estudaram-se os aspectos epidêmicos das infecções de suínos causadas por Streptococcus suis, enfocando, principalmente, a ocorrência de diferentes sorotipos. Foram analisadas 323 amostras isoladas de animais clinicamente doentes, as quais foram sorotipadas de acordo com o procedimento de co-aglutinação. Foi verificado que $\mathrm{S}$. suis está presente em vários estados brasileiros e o maior número de isolados originou-se dos estados de Minas Gerais (62,5\%), São Paulo (10,8\%) e Paraná (9,3\%). O sorotipo 2 foi o mais freqüente (61.0\%), seguido pelos sorotipos 1, 3, 4, 7 e 8. Os isolamentos foram obtidos principalmente de cérebro $(60,1 \%)$ e pulmões $(10,4 \%)$. Os casos de septicemia representaram $9,4 \%$.

Keywords: suíno, Streptococcus suis, sorotipos

\section{INTRODUCTION}

Streptococcus suis is responsible for a variety of infections such as meningitis, pneumonia, septicemia and arthritis. Thirty-five serotypes of $S$. suis have already been identified (1 to 34 and the $1 / 2$ ), with serotypes 2 and 1 being more frequently associated with the disease. However, other serotypes have also been related to infectious incidents in several countries, such as the serotypes $1 / 2,3,4,8,17,19$, and 21 in Canada (Gottschalk et al., 1993); 7, 8, and 14 in the United Kingdom (MacLennan et al., 1996); 1/2, 3, 8, 9, and 14 in Spain (Luque et al., 1998); 3, 4, 7, and 9 in Germany and $1 / 2,3,4,7$, and 9 in Italy (Wisselink et al., 2000).

In the modern Brazilian pig industry, a rapid increase of $S$. suis infections has been observed, but few data exist about serotype distribution and which of these are involved in infectious processes (Santos et al., 2000; Costa et al., 2001). Moreover, the epidemiological aspects of the infections caused by $S$. suis are still unknown.

According to the final report of the National Technical Conference of the Brazilian Swine

Recebido em 19 de março de 2007

Aceito em 14 de abril de 2008

E-mail: aedelarco@hotmail.com 
Veterinary Association on swine streptococci meningitis, one of the Brazilian priorities in swine industry is the characterization of $S$. suis serotypes, as well as the study of risk factors related to the infection (Vaz, 1999). It is increasingly necessary to understand infections caused by $S$. suis because of the increased restriction in antibiotic use in swine production, and the pressure exercised by export industries on antibiotic restriction. Moreover, this agent can be more effectively controlled upon the appropriate vaccine development. The first step in this development is to understand the serotypes involved in the infectious processes. The objectives of this study were to determine the frequency of the serotypes 1 to 9 and $1 / 2$ of $S$. suis in clinically sick pigs, and to study several epidemiological aspects of the infections.

\section{MATERIAL AND METHODS}

The used samples were supplied by the Microvet Laboratory ${ }^{1}$. A total of 323 samples were lyophilized and isolated from the organs of sick animals that had been sent for laboratorial diagnosis from 1995 to 2001. The information from each sample used in this work was: property, municipal district, state, isolation date, animal age, isolation organ, and other isolated bacterial agents.

The samples of S. suis were submitted to standard biochemical testing procedures for identification, in particular, catalase and amilase tests, growth in media with $6.5 \% \mathrm{NaCl}$, and the Voges-Proskauer test (Amass et al., 1997; Luque et al., 1998). Anti-serum was produced to identify the serotype for each sample. This production was necessary due to the lack of sufficient serum-patterns to serotype all of the samples.

Some field samples were selected to serve as standards for the production of antiserum. These sub-samples were identified according to serotype and, the serum-pattern used for the serotypes from 1 to 9 and $1 / 2$. The samples identified by the coagglutination test were used for the production of the antiserum, which was used for serotyping the remaining samples.

${ }^{1}$ Microbiologia Veterinária Especial Ltda. - Viçosa, Brasil.
The immunization of rabbits was adapted from Santos (1997), using three rabbits for each serotype with the samples of $S$. suis defined as a standard, according to Gottschalk et al. (1993). Only the suspensions considered free from contamination were used. For the preparation of the inoculum, oleaginous adjuvant ${ }^{3}$ was added in a concentration of $20 \%$.

In each animal, three applications of the added oleaginous adjuvant bacterial suspension were administered by intramuscular application in the hindslimbs. The first dose of $2 \mathrm{ml}$ was applied as $1 \mathrm{ml}$ on each side of the animal, and the second dose of $1 \mathrm{ml}$ and the third of $2 \mathrm{ml}$ were applied by the same manner. The interval between applications was 15 days. Four days after the last intramuscular application, a series of $0.5 \mathrm{ml}$ of the inactivated bacterial suspension was intravenously applied in the ear marginal vein of the animal, every four days, without the addition of the adjuvant.

Before the animals be killed, they were tested for antibodies, starting from the eighth intravenous application. Antibodies were tested using the agglutination test with 2-mercaptoetanol and the co-agglutination test, according to Gottschalk et al. (1993). Serum positive in the co-agglutination test and that with titer equal or superior to $1: 32$ in the agglutination test were used in this study. The samples with $S$. suis were the same or superior titer for $1: 32$ in the agglutination test were used in this study. The serotyping of the samples of $S$. suis was accomplished according to Gottschalk et al. (1993).

The data given by the Microvet Laboratory and those obtained by the serotyping were compiled and analyzed by the program Epi Info 6.4 .

\section{RESULTS}

Thirty-five (10.8\%) samples were found as negative for $S$. suis in the biochemical tests, but 14 had serotype identified for $S$. suis.

The 323 S. suis samples were taken from 191 properties from different areas throughout the country (Tab. 1). Tree hundred and eight samples $(95.3 \%)$ contained data about the organ from which they were isolated (Tab. 2). Sixty-four samples (19.8\%) were classified as non-serotyped among the serotypes 1 to 9 and $1 / 2$ (Tab. 3). 
Table 1. Distribution of the samples of Streptococcus suis in some Brazilian states

\begin{tabular}{lcc}
\hline State & $\begin{array}{c}\text { Farms/State } \\
(\%)\end{array}$ & $\begin{array}{c}\text { Samples/ } \\
\text { State }(\%)\end{array}$ \\
\hline Bahia & 1.0 & 0.6 \\
Brasília & 1.0 & 0.6 \\
Espírito Santo & 2.1 & 1.5 \\
Goiás & 2.1 & 1.9 \\
Minas Gerais & 59.7 & 62.5 \\
Mato Grosso do Sul & 2.6 & 2.2 \\
Mato Grosso & 0.5 & 0.3 \\
Pernambuco & 0.5 & 0.6 \\
Paraná & 12.6 & 9.3 \\
Rio de Janeiro & 2.1 & 1.2 \\
Rio Grande do Sul & 1.0 & 1.9 \\
Santa Catarina & 3.1 & 6.5 \\
São Paulo & 11.5 & 10.8 \\
Total & 100.0 & 100.0 \\
\hline
\end{tabular}

Table 2. Site of isolation of Streptococcus suis of clinically sick animals

\begin{tabular}{cc}
\hline Isolation site & Isolations (\%) \\
\hline Brain & 60.1 \\
Lungs & 10.4 \\
Septicemia* & 9.4 \\
Brain and lungs & 6.5 \\
Snout & 3.9 \\
Lungs and snout & 3.2 \\
Trachea & 3.2 \\
Joints & 0.3 \\
Other** & 2.9 \\
Total & 100.0 \\
\hline
\end{tabular}

*Related to the isolation of S. suis in three or more different sites in the same animal (for example, brain, lungs and spleen, or brain, lungs, and joints) or with isolation occurring in the spleen or blood collected from the heart. **Isolation in other sites that showed very low occurrence frequencies.

Table 3. Distribution of isolated Streptococcus suis among the 10 tested serotypes

\begin{tabular}{cc}
\hline Serotype & Samples $(\%)$ \\
\hline 1 & 6.8 \\
2 & 61.0 \\
3 & 4.0 \\
4 & 1.9 \\
5 & 0.3 \\
6 & 0.6 \\
7 & 2.2 \\
8 & 2.2 \\
9 & 0.3 \\
$1 / 2$ & 0.9 \\
NS & 19.8 \\
Total & 100.0 \\
\hline
\end{tabular}

NS: non serotyped among sorotypes 1 to 9 and $1 / 2$.
Other bacterial agents were also isolated in the same animal. These isolations occurred concomitantly to the identification of the illness that caused the animal be sent to the Microvet laboratory. One hundred sixty samples (35.9\%) were isolated without another agent being simultaneously present (Tab. 4).

Table 4. Isolated bacterial agents in the same animals with successful isolations of Streptococcus suis

\begin{tabular}{lc}
\hline \multicolumn{1}{c}{ Other agents } & $\begin{array}{c}\text { Samples } \\
(\%)\end{array}$ \\
\hline Actinobacillus pleuropneumoniae & 0.9 \\
Actinobacillus suis & 0.3 \\
Bordetella bronchiseptica & 0.9 \\
Haemophilus parasuis & 13.0 \\
Escherichia coli $\alpha$ hemolytic & 20.1 \\
Escherichia coli $\beta$ hemolytic & 0.9 \\
Pasteurella multocida type A & 2.5 \\
Pasteurella multocida type D & 0.6 \\
Escherichia coli $\alpha$ and $\beta$ hemolytic & 2.2 \\
E. coli hemolytic $\alpha$ and & 7.1 \\
Haemophilus parasuis & 2.2 \\
B. bronchiseptica and $H$. parasuis & 5.3 \\
Multiple agents* & 8.0 \\
Other combinations** & 35.9 \\
Without other isolations*** & 100.0 \\
Total &
\end{tabular}

*Isolation of three or more agents in the same animal.

**Isolations of two agents in the same animal that showed very low occurrence frequencies.

$* * *$ Only $S$. suis isolation.

Nearly all of the $S$. suis serotypes were isolated from the brain. Only serotype 6 was isolated from the lungs and in a case of septicemia.

A total of $142(76.8 \%)$ out of the 185 brain tissue isolations were identified as serotype 2. In 41 cases $(28.9 \%)$, E. coli $\alpha$ hemolytic was isolated; in $10(7 \%)$, Haemophilus parasuis was isolated; and in 53 samples $(37.3 \%)$, no other agent was isolated other than the serotype $2 \mathrm{~S}$. suis.

Five $(21.7 \%)$ out of the 23 non-serotyped samples found in the brain had no other concomitant isolations. Six (26.1\%) were isolated with $E$. coli $\alpha$ hemolytic, and six (26.1\%) with both $E$. coli $\alpha$ hemolytic and $H$. parasuis. 
Nine $(28.1 \%)$ out of the $32 \mathrm{~S}$. suis isolations in the lungs contained $H$. parasuis, while eight $(25.0 \%)$ only contained $S$. suis. When all of the agents that can cause respiratory infections were observed (Actinobacillus pleuropneumoniae, Bordetella bronchiseptica, H. parasuis, Pasteurella multocida $A$ and Pasteurella multocida $D$ ), the total number of samples bearing $S$. suis rose to $17(53.1 \%)$. Ten of these 17 samples belonged to the serotype 2 .

Fourteen samples $(70.0 \%)$ out of the 20 isolated from the brain and lungs belonged to serotype 2 . Six were isolations without other agents, and five contained $H$. parasuis. Two of the three remaining samples contained $H$. parasuis and E. coli $\alpha$ hemolytic.

Serotype 2 was observed in 13 out of the 29 septicemia isolations. Non serotyped samples were observed in 11 isolations. Five of the serotype 2 samples also contained E. coli $\alpha$ hemolytic. Other agents were not isolated in 10 out of the 29 septicemia cases.

A high incidence of infection by $S$. suis was observed in animals over 100-day-old, a divergence from the age more commonly associated in cases of infections by this agent (Tab. 5)

Table 5. Frequency of the age groups of the animals in which samples of Streptococcus suis were isolated

\begin{tabular}{cc}
\hline Age (days) & Number $(\%)$ \\
\hline $0-10$ & 3.2 \\
$11-20$ & 1.4 \\
$21-30$ & 3.7 \\
$31-40$ & 4.1 \\
$41-50$ & 96 \\
$51-60$ & 11.9 \\
$61-70$ & 10.6 \\
$71-80$ & 9.6 \\
$81-90$ & 11.9 \\
$91-100$ & 7.3 \\
$101-110$ & 9.2 \\
$111-120$ & 4.6 \\
$121-130$ & 4.6 \\
$131-140$ & 5.0 \\
$141-150$ & 2.3 \\
$>150$ & 0.9 \\
Total & 100.0 \\
\hline
\end{tabular}

\section{DISCUSSION}

The isolation of S. suis from sick animals in several Brazilian States indicates that this agent is an important cause of infections in the Brazilian pig industry. The greatest occurrence of isolations was found in the state of Minas Gerais. This result can be partially explained by the fact that Microvet Laboratory is located in that State. The isolation and diagnosis services are, therefore, better known in the immediate area. Another reason for the result is the growth of a developed swine production in Minas Gerais, that has increasingly employed modern technology in the production process. The use of technology is generally associated with increased concern for sanitation surveillance to early prevent more effectively the occurrence of disease outbreaks in the swine population.

A significant number of isolations were classified as not serotyped. Testing $S$. suis samples against the serotypes 1 to 34 and $1 / 2$, Higgins and Gottschalk (1999) found that 14\% were not serotyped. This led to the conclusion that other serotypes may play a small role within the studied sample universe. However, this does not likely alter considerably the serotype distribution proposed here. In this study, it was verified that serotype 2 was the most frequently isolated. This has also been verified by other authors that described this serotype as more commonly linked to the infectious processes caused by $S$. suis (Aarestrup et al., 1998; Gottschalk and Segura, 2000).

Not all serotypes or even all the samples of the same serotype are virulent and capable of promoting a disease (Staats et al., 1998). The factors related to virulence continue to be studied to better understand the process. For example, the isolation site of each sample can be used as an assessment tool to identify when the disease is caused by $S$. suis. This is important because $S$. suis is a normal member of the microbiota associated with the upper respiratory tract of swine (Devriese et al., 1994), and can be found there even in cases in which the disease is not present. On the other hand, specimens isolated from the brain are generally associated with primary infection (Sanford and Higgins, 1992). The presence of other microbial agents can also help to elucidate the cases in which $S$. suis is acting as the primary agent. In this study, serotype 2 isolation occurred mostly in 
the brain, agreeing with observations found in the literature. (Mwaniki et al., 1994; Charland et al., 1998; Charland et al., 2000). Therefore, S. suis is likely the primary infection agent in the brain, despite other bacterial agents isolated together with the serotype 2 .

In the cases in which other agents were not isolated, $S$. suis must be the cause of the infection that caused the disease in the animal. Therefore, when $S$. suis was solely isolated in the lungs and snout of sick animals, it was determined as the diseasecausing-agent, despite the low probability occurrence. Care should be taken in respiratory system isolation cases because $\mathrm{S}$. suis has also been associated to other agents which cause diseases in swine (Reams et al., 1996; Gottschalk and Segura, 2000). This suggests that the participation of this bacterium in illnesses of this system is secondary. However, $S$. suis infection can increase the morbidity and mortality of the primary disease, as well as increase weight loss in the affected animals.

The isolations of E. coli $\alpha$ hemolytic and S. suis in the brain of the same animal may indicate that these $S$. suis samples are genuinely virulent and responsible for the disease, independently of its serotype. This result agrees with other findings described in the literature that indicate that virulent samples of S. suis serotypes considered as being of lesser importance can, in fact, cause disease (Gottschalk et al., 1993; MacLennan et al., 1996; Luque et al., 1998; Wisselink et al., 2000). The isolation of $E$. coli $\alpha$ hemolytic does not lead to misdiagnosis, since it is responsible for diarrhea and its participation can, therefore, be secondary. In spite of this, cases of $E$. coli $\beta$ hemolytic isolation are significant because this agent is responsible for the well-known infectious edema disease. This disease also leads to nervous clinical signs and can affect animals of the same age group, as $S$. suis. However, the frequency of isolation was low in this study.

The isolation of $H$. parasuis was extremely important, since this organism is responsible for a disease that can lead to nervous clinical signs. It may also be mistakenly diagnosed as the primary agent, since $H$. parasuis and $S$. suis can affect animals of the same age. In cases in which $S$. suis was isolated in the snout, $H$. parasuis was also present in more than half of the situations. A pre-existing $H$. parasuis infection can excessively multiply the $S$. suis normal to the upper respiratory tract microbiota because of immunologic system depression. These inferences can only be made when $S$. suis is isolated from the snout.

In the serotype $2 S$. suis cases in which isolation occurred amidst widespread infection (septicemia), it is likely that the other isolated agents were secondary to the infection.

According to the literature, a larger occurrence of S. suis infections is expected in animals around 42-days-old (Sanford and Higgins, 1992). Therefore, the high frequency of $S$. suis infection found in old animals was a divergence from the age more commonly associated in infections by this agent. The late appearance of these infections is likely caused by the use of medication to control infectious agents. This is applied through the feed for a period of one week before the age associated with disease onset. This treatment may be controlling $S$. suis in the age group in which it is reported as being found more frequently. However, bacteria that were not eliminated by this treatment can multiply again over time and cause the appearance of clinical cases in older animals.

\section{CONCLUSIONS}

It can be concluded that $S$. suis is a bacterium that is present in the swine production of several Brazilian states. The serotype 2 is the greatest contributor to infectious processes. The affected age group encountered in Brazil, especially in Minas Gerais State, is greater than that reported in other countries.

\section{ACKNOWLEDGEMENTS}

This study was supported by PADCT/MCT, Brazil.

\section{REFERENCES}

AARESTRUP, F.M.; JORSAL, S.E.; JENSEN, N.E. Serological characterization and antimicrobial susceptibility of Streptococcus suis isolates form diagnostic samples in Denmark during 1995 and 1996. Vet. Microbiol., v.60, p.59-66, 1998.

AMASS, S.F.; SANMIGUEL, P.; CLARK, L.K. Demonstration of vertical transmission of 
Streptococcus suis in Swine by genomic fingerprinting. J. Clin. Microbiol., v.35, p.15951596, 1997.

CHARLAND, N.; HAREL, J.; KOBISH, M. et al. Streptococcus suis serotype 2 mutants deficient in capsular expression. Microbiology, v.144, p.325-332, 1998.

CHARLAND, N.; NIZET, V.; RUBENS, C.E. et al. Streptococcus suis serotype 2 interactions with human brain microvascular endothelial cells. Infect. Immun., v.68, p.637-643, 2000.

COSTA, A.T.R.; REIS, R.; LOBATO, F.C. et al. Sorotipificação e avaliação da patogenicidade de amostras de Streptococcus suis isoladas de suínos. In: CONGRESSO BRASILEIRO DE VETERINÁRIOS ESPECIALISTAS EM SUÍNOS, 10., 2001, Porto Alegre. Anais... Porto Alegre:[s.n.] 2001. CD-ROM (Resumo).

DEVRIESE, L.A.; HOMMEZ, J.; POT, B. et al. Identification and composition of the streptococcal and enterococcal flora of tonsils, intestines and faeces of pigs. J. Appl. Bacteriol., v.77, p.31-36, 1994.

GOTTSHALK, M.; HIGGINS, R.; BOUDREAU, M. Use of polyvalent reagents for serotyping of Streptococcus suis. J. Clin. Microbiol., v.32, p.2192-2194, 1993.

GOTTSCHALK, M.; SEGURA, M. The pathogenesis of meningitis caused by Streptococcus suis: the unresolved questions. Vet. Microbiol., v.76, p.259-272, 2000.

HIGGINS, R.; GOTTSCHALK M. Distribution of Streptococcus suis capsular types in 1998. Can. Vet. J., v.40, p.277, 1999.

LUQUE, I.; TARRADAS, C.; ARENAS, A. et al. Streptococcus suis serotypes associated with different disease conditions in pigs. Vet. Rec., v.27, p.726-727, 1998.

MacLENNAN, M.; FOSTER, G.; DICK, K. et al. Streptococcus suis serotypes 7, 8 and 14 from diseased pigs in Scotland. Vet. Rec., v.26, p.423424, 1996.
MWANIKI, C. G.; ROBERTSON, I. D.; HAMPSON, D. J. The prevalence of Streptococcus suis type 2 in Western Australian piggeries. Aust. Vet. J., v.71, p.385-386, 1994.

REAMS, R.Y.; HARRINGTON, D.D.; GLICKMAN, L. T. et al. Multiple serotypes and strains of Streptococcus suis in naturally infected swine herds. J. Vet. Diagn. Invest., v.8, p.119121, 1996.

SANFORD, S.E.; HIGGINS, R. Streptococcal diseases. In: LEMAN, A.D.; STRAW, B.E.; MENGELING, W.L., D'ALLAIRE, S., TAYLOR, D.J. (Ed.) Diseases of Swine. Ames: Iowa State Univ., 1992. p.588-590.

SANTOS, J.L. Epidemiologia e controle da infecção por Haemophilus parasuis. 1997. 139f. Tese (Doutorado) - Escola de Veterinária, Universidade Federal de Minas Gerais, Belo Horizonte.

SANTOS, J.L.; DEL'ARCO, A.E.; RIBEIRO, M.C.E. et al. Occurrence of Streptococcus suis serotypes in pigs in Brazil. In: INTERNATIONAL PIG VETERINARY SOCIETY CONGRESS, 16., 2000, Melborne. Anais... Melborne: [s.n.] 2000. p.536. (Resumo).

STAATS, J.J.; PLATTNER, B.L.; NIETFELD, $\mathrm{J}$. et al. Use of ribotyping and hemolysin activity to identify highly virulent Streptococcus suis type 2 isolates. J. Clin. Microbiol., v.36, p.15-19, 1998.

VAZ, A.K., 1999. Relatório da reunião final. In: SIMPÓSIO SOBRE MENINGITE ESTREPTOCÓCCICA SUÍNA E PLEUROPNEUMONIA SUÍNA, 1999, Lages. Anais... Lages: [s.n.] 1999. p.42-44.

WISSELINK, H.J.; SMITH, H.E.; STOCKHOFEZURWIEDEN, N. et al. Distribution of capsular types and production of muramidase released protein (MRP) and extracellular factor (EF) of Streptococcus suis strains isolated from diseased pigs in seven European countries. Vet. Microbiol., v.74, p.237-248, 2000. 